what he sees, and frequently he will make a diagnosis only when he hears his own description of a lesion. An extension of this, perhaps more relevant for the house physician or registrar, is learning to write down a really accurate description of a lesion, including, when suitable, precise measurements. This not only teaches accuracy of observation but is of great value if the patient is seen again later, possibly by somebody else. It is also important for the student or trainee to commit himself to a firm attempt at a diagnosis, preferably in writing, so that he learns to make up his mind and not just leave a vague query in the hope that something will turn up in the laboratory reports.

Having said all this, one must not overdo the importance of morphology. Jackson" quotes "the age-old dermatological practice of looking first and talking afterwards"-which has been responsible for much of the lack of esteem with which dermatologists have been regarded in the past. Dermatology is an integral part of medicine just as much as cardiology or neurology, and the approach to patients with skin disease should be the same as to those suffering from diseases of the heart or nervous system, etc. The first step must be a careful and detailed history, not only to get the facts but also to establish rapport. Then follows a physical examination, which (except in obviously localised lesions like a rodent ulcer) must include the whole of the patient's skin and often other systems - just as in a patient with disease of the stomach or chest. Laboratory investigations may be required in some patients but should supplement and not replace the clinical examination. Too much dependence on these tests could lead to computerised medicine, but the value of a computer depends on the quality of the material fed into it, and this can be adequate only if it is based on accurate history taking and clinical observation.

1 Jackson, R, Archives of Dermatology, 1975, 111, 632.

\section{Calculating idiots}

For longer than medical records have been kept people have intrigued (or frightened) themselves with the possibility that madness, foolishness, and eccentricity are often accompanied by some extraordinary or supernatural powers-clairvoyance, magic, healing, or memory. In the words of Dryden, "Great wits are sure to madness near allied, and thin partitions do their bounds divide." An idiot savant is a person of subnormal general intelligence who nevertheless excels in certain unusual skills, such as playing musical instruments or numerical computation. Such individuals were the source of great scientific interest in the 19th century, but they are studied in detail less often nowadays. Neverthelss, $\mathrm{Hill}^{1}$ has recently given a detailed account of an idiot savant, described in the traditional way as "B."

B was born in 1921, found to have congenital syphilis, and sent to state schools for the mentally retarded. He had an IQ of 54 at the age of $6 \frac{1}{2}$ but qualified as an idiot savant by being able to play eleven instruments by ear, by his drawings, and by a remarkable memory for dates. He was especially successful in "calculating" the calendar (a skill commonly found in idiots savants). He could name the days of the week on which particular dates fell with better than $80 \%$ reliability. Hill points out that there is a straightforward formula for solving such problems, but that his extremely poor general mathematical ability compared with the facility with which he was able to calculate the calendar (in a reaction time of a few seconds) makes it unlikely that B was using a numerical method.
Hill also dismisses another standard explanation of this skill: eidetic or photographic memory. B's pictorial memory was in fact very poor, as was his ability to associate dates with photographs of people. A thorough test of his calendar calculation did show up certain peculiarities: he had particular difficulty with dates in the first half of the years 1941, 1947, 1958, and 1969 , all of which began on a Wednesday. There was no evidence, however, that he was organising his recall around certain key dates (perhaps important days in his life), because there was no other tendency for reaction time or accuracy to vary systematically. Unfortunately, Hill does not mention whether B could calculate dates in the future, or before his own infancy, so we do not know whether he was using a global method or one restricted within his own life span and conceivably tied to memory of personal experiences.

Intelligence testers constantly run up against the problem of devising universal methods for measuring something that does not express itself in a single faculty. We happily recognise that a child may be selectively gifted-having a natural flair for music, graphic art, or language-though possibly unexceptional in every other way. Curiously, many special skills which leave the ungifted layman breathless have in common a certain mechanical nature. Perhaps we should be more impressed by commoner powers that our intellects give us. By any objective criterion calendar calculation is a trivial task compared with such feats as recognising a person's face or even driving a car. Foreigners used to view the average Englishman's ability to do running calculations in pounds, shillings, and pence with the kind of awe and reverence that calendar calculation also provokes.

Hill concluded that the idiot savant may have an unusual ability to focus his attention on the learning of dates by rote for long periods without becoming bored. Thank heaven for boredom.

${ }^{1}$ Hill, A Lewis, American fournal of Psychiatry, 1975, 132, 557.

\section{Royal Commission on the NHS}

On Monday 20 October the Prime Minister formally announced in Parliament a Royal Commission "To consider in the interests both of the patients and those who work in the NHS the best use and management of the financial and manpower resources of the NHS" (see p 235). So after stonewalling the medical profession's repeated requests during the past year or so for an inquiry into NHS financing the Government has now done a smart about turn. Nevertheless, it has tried to pre-empt what should be an essential part of the commission's inquiries by announcing that its plans for separating private practice from the NHS are to proceed. Any chairman - and as we went to press no name has been announced -worth his salt, however, should not let that statement of intent hinder the commission's work. Furthermore, the profession should have no difficulty in convincing the commission's members that independent practice in and outside the NHS has some effect on the Service's finances and a profound effect upon its manpower. The profession's leaders will, no doubt, have made this point to Mr Wilson when he met them on 21 October after we went to press. But, having made their protest about the Government's foolish opening gambit, doctors should set to work on their evidence. Their aim should be to make sure that the outcome of the Royal Commission is a great improvement in the service for the patient. 